\title{
Charcoal heaps volume estimation based on unmanned aerial vehicles
}

\author{
Luiza Marina Esteves de Carvalho ${ }^{1}$ \\ Alessandra Melo² \\ Glauco José de Matos Umbelino ${ }^{3}$ \\ Jan-Peter Mund ${ }^{4}$ \\ Jhonathan Gomes dos Santos ${ }^{5}$ \\ Jacqueline Rosette ${ }^{6}$ \\ Daniel Silveira ${ }^{7}$ \\ Eric Bastos Gorgens²
}

1. Programa de Pós Graduação em Ciência Florestal. Universidade Federal dos Vales do Jequitinhonha e Mucuri. Brazil. luizacarvalhoflo@gmail.com

2. Departamento de Engenharia Florestal. Universidade Federal dos Vales do Jequitinhonha e Mucuri. Brazil.mmelo.alessandra@gmail.com;

eric.gorgens@ufvjm.edu.br

3. Departamento de Geografia. Universidade Federal dos Vales do Jequitinhonha e Mucuri. Brazil.glauco.umbelino@ufvjm.edu.br

4. Hochschule für nachhaltige Entwicklung Eberswalde. Germany. Jan-

Peter.Mund@hnee.de

5. Campus de Engenharias e Ciências Agrárias. Universidade Federal de Alagoas.

Brazil.jhonathan.santos@ceca.ufal.br

6. Geography Department. Swansea University. Wales. United Kingdom.

j.a.rosette@swansea.ac.uk

7. Bracell SP, P\&D Florestal, Lençóis Paulista, São Paulo.

danielsilver007@hotmail.com

${ }^{*}$ Corresponding author. 


\section{Abstract}

The charcoal stock in a forest company is controlled based on the theoretical capacity of the masonry ovens (input) and shipped trucks (output). During the year, the company must monitor the stock for the purposes of accountability reports. This study proposes a more efficient and equally precise survey method that overcomes the challenges of the common monitoring system in Brazil. During this study, a new monitoring method based on digital stereoscopy from UAV images was developed, implemented and evaluated. The results were compared with a traditional topographic survey.

A masonry oven's complex containing eight charcoal heaps was flown and surveyed using a multi-engine UAV, with an integrated Global Navigation Satellite System (GNSS) and RTK equipment. Two stereoscopic processing methods were applied: (1) very low quality and (2) high quality to image alignment, reconstruction of the dense cloud, face count and in three-dimensional mesh creation. Low quality products showed geometric deformities when compared to high quality, but resulted in similar estimation to the topographic survey.

The results indicated that the charcoal heaps' volume estimation using UAV derived orthomosaics can replace the conventional method of GNSS RTK surveys with considerable gains in stockpile volume accuracy, inventory frequency, and safety. In the case of high accuracy parameterization, improvements in geometric precision and accuracy are also produced.

Keywords: Charcoal production monitoring, UAV, Brazil; volume calculation. 


\section{Introduction}

In the past, charcoal was one of the main fuels in terms of heating value, availability, storage and transportation on a worldwide level (Krebs et al. 2017). In much of the global south, charcoal is still a very popular domestic fuel, and retains a regional market importance as a reducer in metallurgical processes for pig iron production (Santos, 2020). For that reason, despite the incentives to transition to new energy matrices, the regional demand for charcoal is still growing (Okode et al. 2020).

Brazil in particular has been the world's largest charcoal producer for many years (Chidumayo, \& Gumbo, 2013). Charcoal may be produced from wood, agro-industrial residues and other forms of biomass, which are carbonized under controlled conditions in a confined space (Nabukalu\& Gieré, 2019). The production system differs widely between countries, but always follows three main stages driven by temperature: drying, pyrolysis and cooling (Seboka, 2009). After the pyrolysis process, the coal is removed from the masonry ovens and transferred to the yard for finish the cooling process, where it remains until transport. Charcoal production units run by large producers like the site studied here are sustained entirely by forest plantations, and are fully mechanized (Figure 1).

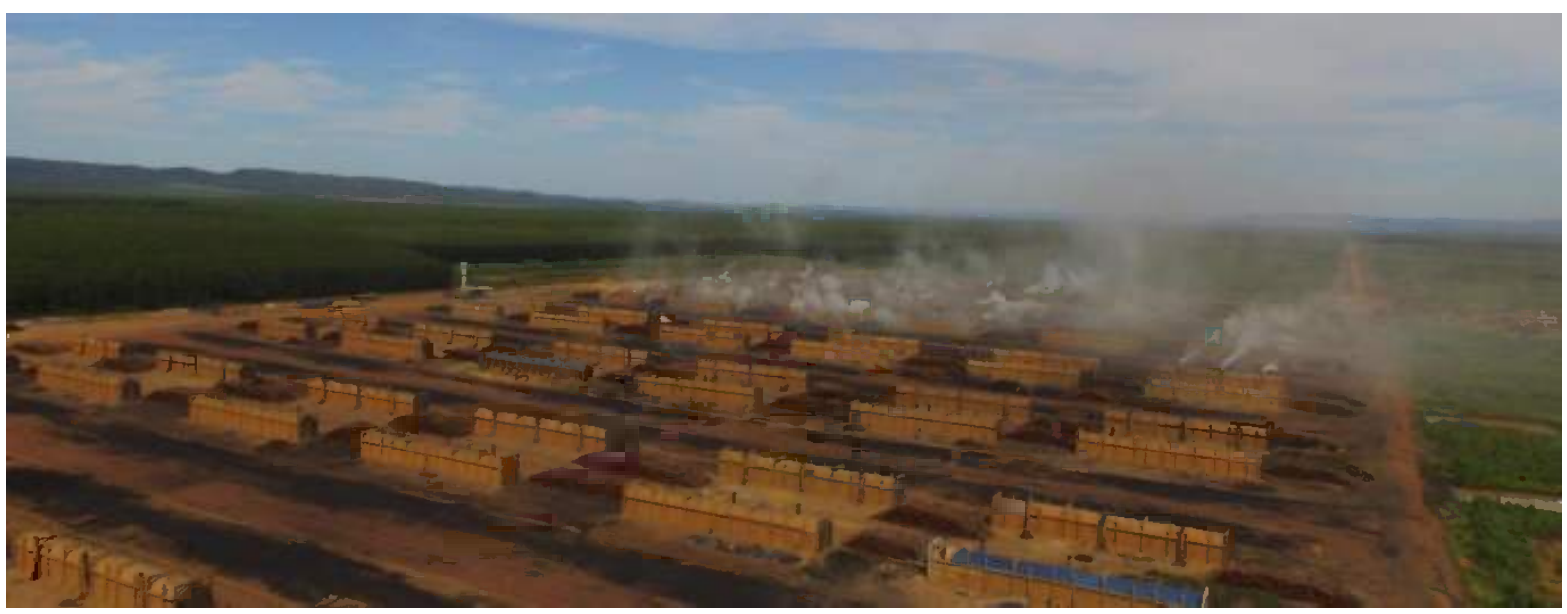

Figure 1. Charcoal production site composed by batteries of masonry ovens intercalated by charcoal and wood yards. 
Throughout a regular year, the charcoal stock is controlled based on the theoretical capacity of the masonry ovens (input) and shipped trucks (output). During the year, the company will perform two topographic surveys (once every six months) to update and correct the charcoal inventory, and perform accountability reports for stakeholders. This method measures the exact positions of a collection of ground control points around and on the charcoal heaps (Figure 2a), allowing the volume of the heaps to be calculated (Oliveira et al. 2015) (Figure 2b). The survey equipment applied for this method is usually a global navigation satellite system receiver (GNSS) based on real time kinematic positioning (RTK) (Busnello et al. 2016). This technology is limited to $20 \mathrm{~km}$ radius from the base station (stationary), and can suffer from interference from obstacles between the base and the receiver (Feng et al. 2020).

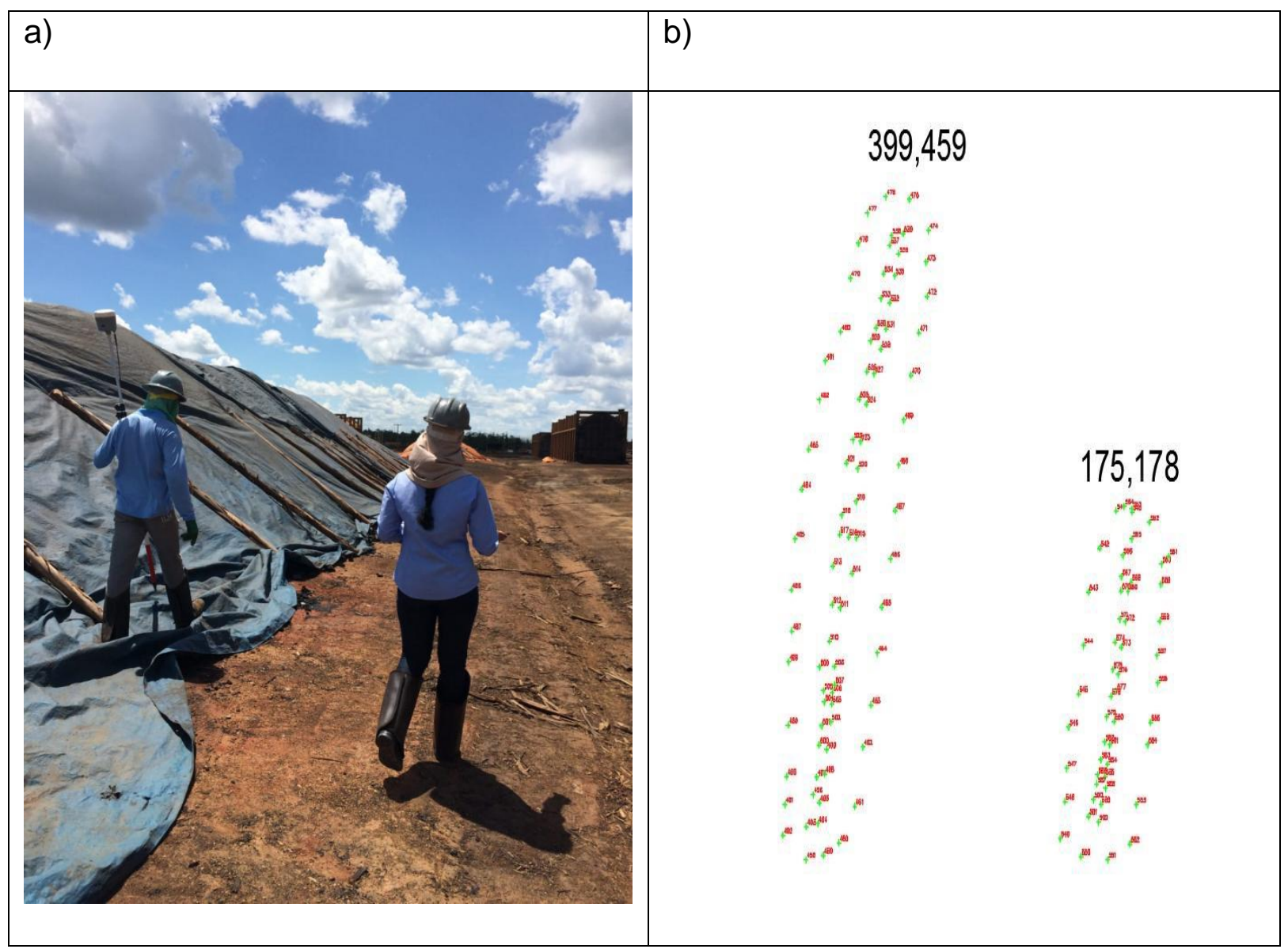

Figure 2. In a) the topographic survey of the charcoal heap. One worker carries the GNSS antenna while walking over the heaps and the second worker carries the handheld computer and registered the sampling points. In b) the recorded 


\section{points from two charcoal heaps and the volume in $\mathrm{m}^{3}$ computed by the topographic software.}

The most important limitations of only two inventory checks are: (1) the surveying service is usually provided by contractors who work for several companies, including mining companies, (2) the method applied requires worker mobilization to visit the charcoal production sites that are spread across different regions, (3) the volume calculation based on the collected data is not integrated into the charcoal company's accounting or production monitoring system. The low frequency of stock volume surveys is usually reflected as a time-lag in records and unreliable stocks.

The increase in availability and reduction in cost of Unmanned Aerial Vehicles (UAV) and the use of digital stereoscopy offers an unique opportunity for a complete tri-dimensionalization of the stockpile and for semi-automatic volume computation. Several studies published information about proven applied technologies for estimating the above-surface volume of objects like olive tree lines (Anifantis et al. 2019); wood chip piles (Mokros et al. 2016; Mund, et al 2017); wood log piles in sawmill yards (Figueiredo et al. 2016); quarries (Raeva et al. 2016); and water tanks (Ab Rahman et al. 2017). Technical advantages of UAV approaches for volume calculations are the positional accuracy, high spatial resolution, good quality/cost ratio, and the remarkable opportunity to implement a high temporal resolution surveys at local scale (Parra et al. 2017). The ability to quantify assets remotely has added benefits of improved safety of workers avoiding the need to climb on the stockpile.

In forestry, UAV photogrammetry has been studied for forecasting biomass stock (Giavennetti et al. 2018), modeling the density of the trees and the height of the canopy (Puliti et al. 2019), estimation of biophysical properties (Ota et al. 2017), tree height measurements (Krause et al. 2019), wood log piles monitoring (Figueiredo et al. 2016) and three-dimensional reconstruction of the canopy (Jayathunga et al. 2018). UAV short-range photogrammetry is a tool that allows high precision in its results, especially when combined to control ground points (Anifantis et al. 2019). However, UAVs have so far only been used in exceptional cases to 
determine the volume of wood piles or to measure large quantities of bulk material stored in various raw materials from the air. Until now there has been no study published that relates UAV photogrammetry surveys to charcoal heap monitoring.

We aim to propose a more efficient and equally-precise survey method that overcomes the above mentioned challenges in monitoring charcoal large-scale production system in Brazil. Therefore this paper develops and evaluates a new charcoal production monitoring method based on digital stereoscopy from UAV images and compares results with traditional topographic surveys.

\section{Materials and methods}

The empirical study was carried out at a charcoal production site located in Vazante, Minas Gerais, Brazil. The charcoal production site is composed of a complex of masonry ovens intercalated by ranks of wood piles, and rwos of charcoal heaps. In this location, each complex is formed of 2 lines of 6 ovens, externally bounded by a wood yard and internally divided by a charcoal yard (Figure 3). 


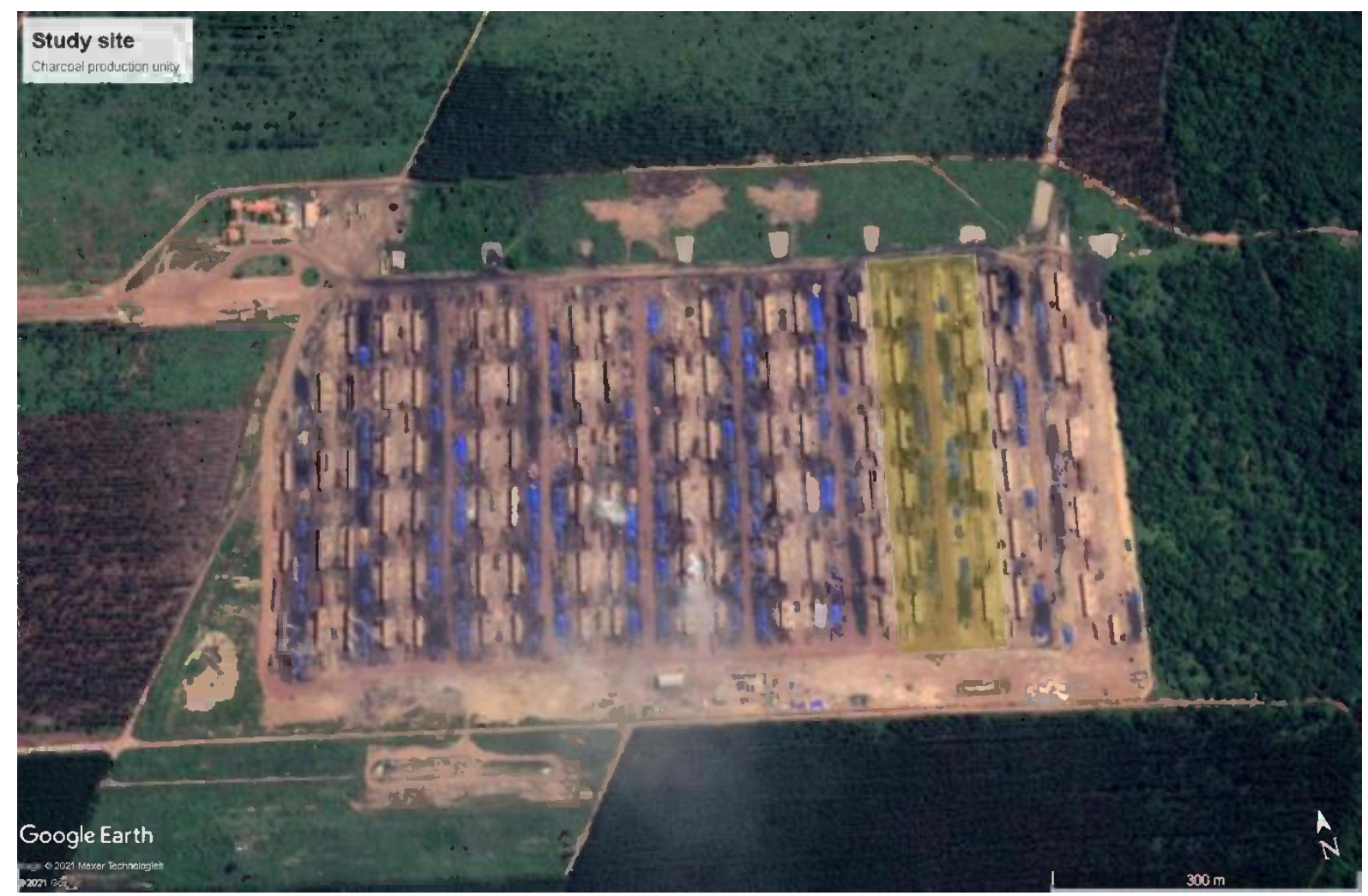

Figure 3. Production charcoal site composed by 9 masonry ovens complexes. The complex highlighted in yellow comprises this study area.

We flew one masonry ovens complex (5 hectares) containing eight charcoal heaps. A DJI Phantom 3 Standard multi-rotor UAV, with an integrated Global Navigation Satellite System (GNSS), was used to collect the stereoscopic images. The camera has 12 Megapixels and a focal length of $20 \mathrm{~mm}$, supported by a three-axis gimbal. The flight was performed in $20^{\text {th }}$ March, 2018, during the morning ( 9AM). The sky was sunny, with isolated clouds, no rain, and average temperature of $23^{\circ} \mathrm{C}$. The charcoal production site has a constant smoke, specially around ovens that are in the drying stage, however charcoal heaps is associated with empty ovens (end of pyrolysis process). During the data collection, a soft wind was carrying the smoke to the opposite direction of the study area, allowing a completely clear view of the oven's complex.

The flight plan was deployed by an iPhone 5s, with iOS version 11.3.1 using the Pix4D Capture application. A double grid crossed at 90 degrees was used, ensuring multilateral imaging (Figure 4). The camera's angle was set at $70^{\circ}$ and the images overlapped $72 \%$ lateral e $80 \%$ frontal. The flight height was 80 meters above 
local ground level, resulting in a constant ground sampling distance (GSD) of 1.86 $\mathrm{cm}$ pixel $^{-1}$. These settings were defined based on pilot experience and published results to ensure an accurate three-dimensional reconstruction (Figueiredo et al. 2016; Parra et al. 2017, Mund et al. 2017).

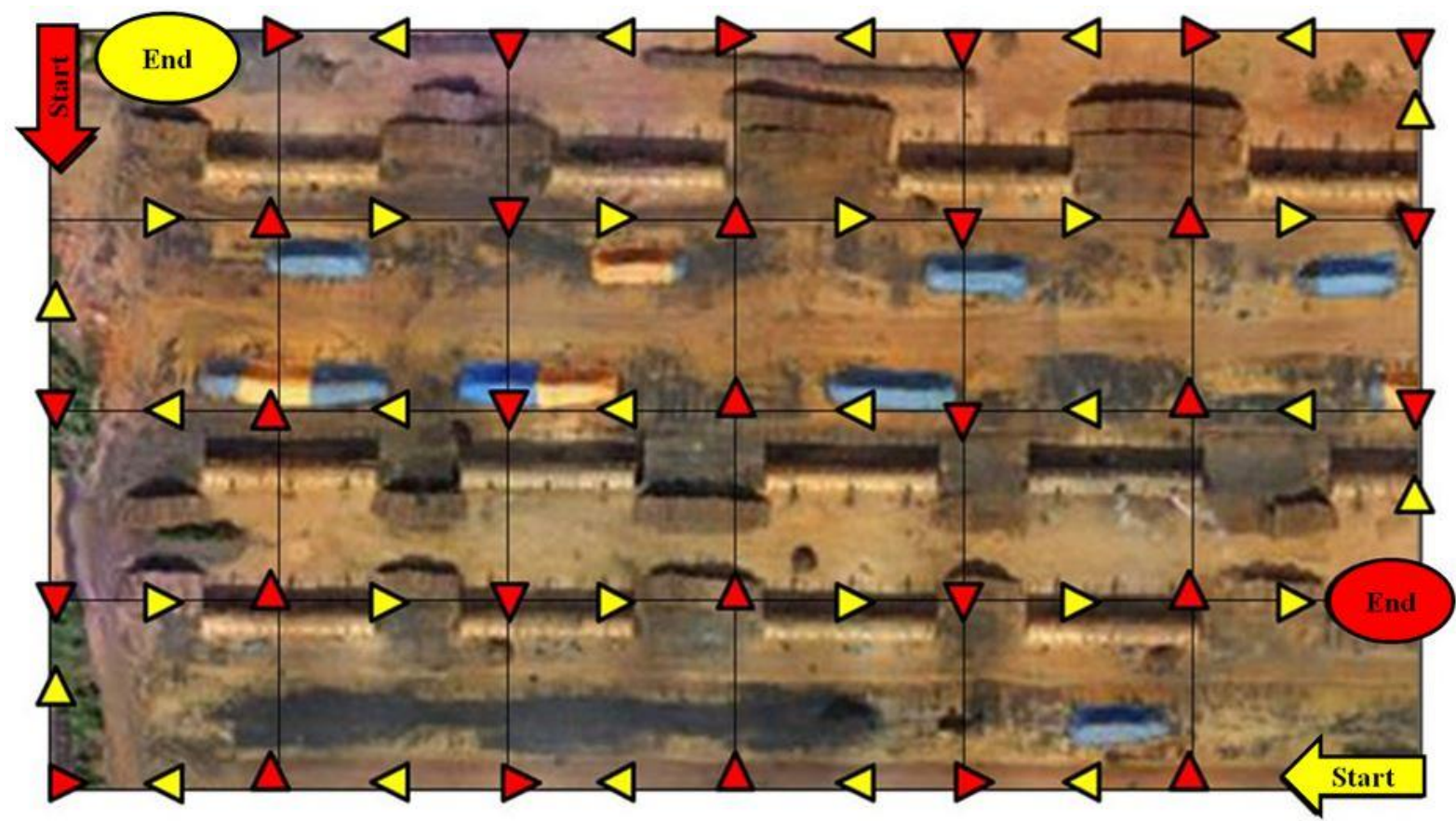

Figure 4. Double grid sampling scheme with surveying paths crossing each other at 90 degrees.

The digital orthomosaic (DOM) and digital surface model (DSM) were created using a photogrammetric approach based on "Structure from Motion" (SfM). The volumetric calculation of the eight charcoal heaps was carried out in seven steps, where five steps are part of the image mosaicking algorithm: feature point extraction, image registration, homography computation, warping and blending and generating the orthomosaic image (Gosh et al. 2016); followed by three steps for the 3D reconstruction: dense cloud creation, three-dimensional triangulated point mesh, and digital surface model (DSM) creation (Long et al. 2018; Marushko 2019).

Seven georeferenced points distributed on the masonry ovens corners (permanent marks) in the surveyed complex were selected to be used as control points (GCPs). These points were detected and marked in the aerial images in order 
to check positioning errors, assisting in image calibration and in spatial referencing (Parra et al. 2017). The image processing was performed using the Agisoft Metashape Professional software, version 1.6.2, specialized in digital stereoscopy (see Table 1 for the complete parametrization). The hardware used for processing was a computer with a Core i9 processor, $2.9 \mathrm{Ghz}, 24$ cores, 128GB of RAM, GPU GTX 1070 8GB and a 64-bit operating system.

Table 1: Parametrization for processing the volume charcoal heaps.

Processing steps

Alignment

Accuracy: Lowest and High

No generic preselection

Reference preselection

Key point limit: 40000

Tie point limit:4000

Not masks applied

Adaptative camera model fitting

Alignment optimization

Fit f: yes

Fit cx, cy: yes

Fit b1, b2: no

Fit k1, k2, k3: yes

Fit k4: no

Fit p1, p2: yes

Fit p3, p4: no

No adaptative camera model fitting

Dense cloud 
Depth filtering: aggressive

Do not reuse depth maps

Calculate point colors

Build mesh

Source data: dense cloud

Surface type: height field

Quality: Lowest and High

Face count:Lowest and High

Interpolation enabled (default)

All point classes

Do not use strict volumetric masks

Do not reuse depth maps

DSM

Projection: SIRGAS 2000 UTM 23S

Source data: dense cloud

Interpolation enabled (default)

All point classes

Orthomosaic

Projection: SIRGAS 2000 UTM 23S

Surface: DEM

Blending mode: DEM

Enable hole filling

In the experiment we investigated two processing methods and their influence on the precision of the volume calculation: very low quality parametrization to image alignment, reconstruction of the dense cloud, face count and threedimensional mesh creation (M1) and high quality to image alignment, reconstruction 
of the dense cloud, face count and in three-dimensional mesh creation (M2). Reducing the quality parameters impacts the resolution of the input images, as a results it will produce lower number of points, larger GSD, and lower geometry precision. The stereoscopic image processing generated two different DSMs and two orthomosaics, one from each processing method. The volume of each charcoal heap was then calculated and quantified.

The volumetric estimates of the 8 charcoal heaps obtained using UAS stereoscopic imagery were compared with results of the traditional topographic methodology. The RTK fixed base was tracking the satellites for approximately 3 hours, to stabilize the accuracy of the coordinates. In total, 428 points were collected along the eight heaps, requiring two people for the survey: one person walking with the GNSS antenna, while the other person recorded the points with the handheld computer. For safety reasons, the antenna and the handheld devide could not be operated by the same person. Around one and half hours was necessary to perform the RTK survey of the studied area. The RTK collection, data processing and volume calculation are performed by the contractor, and the final volume calculations of the heaps were used in comparisons to this study. The real volume is very hard to be determined. When transported, heaps are usually mixed to fill the truck capacity, and the transportation controls are based on weight. Due to this limitation, the comparison was operational and technically oriented, comparing procedures estimations.

The topographic 3D polygon for each charcoal heap was built connecting the edge points obtained by the RTK field survey. The same polygons were used further on to guarantee a comparison of the respective object volume. The estimated volumes by the topographic method were compared with M1 and M2 processing results of the aerial UAV orthomosaics. A pair-wise comparison was made using the F-Graybill hypothesis test (Graybill 1976): RTK with M1; and RTK with M2 (for a level of significance of $5 \%$ ). This test also analyzes the variance and not just the average as in usual hypothesis tests. The F Value is calculated using the formula:

$$
F=\left(S_{1} E_{1}-S S E_{2} / m\right) / S S E_{2} / n-k \text {, }
$$


where SSE = residual sum of squares, $\mathrm{m}=$ number of restrictions and $\mathrm{k}=$ number of independent variables (Graybill 1976).

\section{Results}

The flight area covered approximately 7.6 hectares, extrapolating the 5 hectares to ensure complete coverage of the charcoal heaps. The flight took 13 minutes, recording 380 images. For both processes (M1 and M2), the image alignment quality was higher than 0.7 pixel, allowing all images to be included in the point cloud creation. M1 took approximately 24 minutes, while M2 took about 11 hours and 27 minutes.

All the products from M2 have a much higher quality (less distortion, high accuracy and high resolution) when compared to M1 (Table 2) but its processing cost is 28 times longer than in M1. The cloud produced by M2 was 94 times denser than the one produced by $\mathrm{M} 1$; the number of faces in the three-dimensional mesh produced by $\mathrm{M} 2$ is 853 times higher than $\mathrm{M} 1$. The digital surface model resolution was about $26.3 \mathrm{~cm} \mathrm{px}^{-1}$ for $\mathrm{M} 1$ and $3.16 \mathrm{~cm} \mathrm{px}^{-1}$ for $\mathrm{M} 2$ respectively. It was possible to notice that the sparce point cloud produced by M1 had geometric deformities in the masonry ovens and in the geometry of the charcoal heaps, which did not happen in the sparce cloud produced by M2.

Table 2. Number of points in the dense cloud, numbers of faces in the threedimensional mesh, digital elevation model resolution $\left(\mathrm{cm} \mathrm{px}^{-1}\right)$ for both experiments. M1 and M2 represent very low and high quality algorithm parameters during photogrammetry computation in Agisoft Metashape.

\begin{tabular}{ccc}
\hline Variables & M1 & M2 \\
\hline Number of points in the dense cloud & $1,324,346$ & $125,615.683$ \\
$\begin{array}{c}\text { Number of faces in the three-dimensional } \\
\text { mesh }\end{array}$ & 29,429 & $25,123,136$ \\
DSM resolution $\left(\mathrm{cm} \mathrm{px}^{-1}\right)$ & 26.3 & 3.16
\end{tabular}


M1 consistently reported lower heap volumes when compared to $\mathrm{M} 2$, and M1 values were closer to those volumes calculated based on the RTK points (Table 3). $\mathrm{M} 1$ differed in average by $14.372 \mathrm{~m}^{3}(6.54 \%)$ to RTK; and M2 differed in average by $18.518 \mathrm{~m}^{3}$ (7.89\%) when compared to RTK. Testing the results using the FGraybill hypothesis test, there was no statistical differences between RTK and M1 $(p$-value $=0.8115)$, while statistical differences was found between RTK and M2 ( $p$ value $=0.001078)$ 
Table 3 - Charcoal heap volume in $\mathrm{m}^{3}$ of volume estimation method, where RTK represents the topographic method, and M1/M2 represent very low and high quality during photogrammetry computation algorithm parameters in Agisoft Metashape respectively.

\begin{tabular}{cccc}
\hline Heap & M1 & M2 & RTK \\
\hline $\mathbf{1}$ & 414,995 & 437,823 & 399,459 \\
$\mathbf{2}$ & 158,928 & 170,836 & 175,178 \\
$\mathbf{3}$ & 334,994 & 382,018 & 353,921 \\
$\mathbf{4}$ & 143,321 & 161,246 & 149,692 \\
$\mathbf{5}$ & 277,708 & 270,915 & 243,431 \\
$\mathbf{6}$ & 185,807 & 194,657 & 179,501 \\
$\mathbf{7}$ & 129,067 & 152,746 & 143,105 \\
$\mathbf{8}$ & 148,669 & 165,443 & 151,936 \\
\hline Sum & $\mathbf{1 . 7 9 3 , 4 8 9}$ & $\mathbf{1 . 9 3 5 , 6 8 4}$ & $\mathbf{1 . 7 9 6 , 2 2 3}$ \\
\hline
\end{tabular}

\section{Discussion}

The experiment was designed to contrast the UAV survey to the standard approach. To understand the real gains and limitations, the RTK survey was performed by the same contractor that usually delivers the results to the company where the experiment was performed. Our results prove with empirical and statistical evidence that the suggested UAV based aerial orthophoto method has potential for replacing or complementing the conventional RTK approach.

The RTK approach is the conventional method to estimate the charcoal heaps volume, and it is not usually integrated in the forestry companies' expertise. Thus, the RTK survey service is usually provided by an external contractor twice per year. As a result, the cost is high and the processing flow slower, since it requires the displacement of a team for the field survey, followed by processing in the office and subsequent delivery of the report to the forest company.

On other hand, UAV surveys have been incorporated into the forest company for several other applications ranging from silviculture to logging 
(Giannetti et al. 2018, Oliveira et al. 2020, Gülci et al. 2021, Dainelli et al. 2021). To proposed expanded utilization of UAVs is highly advantageous to amortize the value invested into the technology, to utilise in-house skills and to provide time and cost savings.

Although there are only a few studies using photogrammetry to estimate heaps volume elsewhere, accuracy improvements have been consistently reported (Mokros et al. 2016; Raeva et al. 2016; Ab Rahman et al. 2017). A study comparing volumetric estimation in a quarry, combining GNSS data and UAV images resulted in an error of approximately 3\% (Raeva et al. 2016). In another study, the digital stereoscopy from UAV images obtained a $5 \%$ error in estimating the volume of a water tank (Ab Rahman et al. 2017).

The three-dimensional reconstruction quality depends on the parameterization used (Iglhaut et al, 2019), in particular on three parameters from stereoscopic processing directly influence volumetric estimation: (1) the image alignment accuracy (responsible for estimating the camera's position and image internal and external orientation); (2) the quality parameter in the point cloud densification (responsible for geometric precision); (3) and the quality parameter, number of faces of the three-dimensional mesh specified by the maximum number of polygons in the final mesh (Agisoft, 2020). For this reason, the results obtained by $\mathrm{M} 2$ are technically closer to the real geometry and volume, when compared to M1. As M1 and RTK were statistically similar producing lower volumes it is possible to assume that the conventional method based on RTK is underestimating the charcoal volume in the official inventory. The lower resolution resulted from low quality parameterization and the relative low number of point collected by the RTK simplifies the topography (cutting off small variations). M2 products showed a greater number of points in both clouds and a greater number of faces when compared to M1. The reason is that the criteria for choosing these points are different for each process, and much more demanding in $\mathrm{M} 2$.

Previous studies concluded that the quality of the point cloud is influenced by the processing parameterization, and the processing speed can also be improved by the hardware components (lqbal et al. 2018). The higher the processing quality of 3D point clouds and meshes, the bigger the number of key points and the higher the 
resulting geometric precision, at the cost of more processing time on an i9 processor/GTX. In this study, while low quality point cloud processing took about 30 minutes, the high quality processing took almost 12 hours. The stereoscopic processing could be implemented by the forest company, since the same processing steps will be used for silviculture, forest inventory, logging or volume estimation. Even an 12 hours processing time is not prohibitive comparing to the RTK pipeline which takes several days for the results to be received.

Although during this experiment we did not face problems related to smoke and dust exhausting from the masonry ovens, it has to be considered as a potential problem. Those issues could reduce the image quality and compromise the orthophotomosaic generation as well as overheating of the UAV system and reducing the range of the UAV remote controller. However, the UAV survey could be easely adapted based on local wind diection to provide better visual conditions.

The suggested innovative survey method has additional direct gains in survey frequency and employees' safety, which have not yet been analyzed in this experiment. The surveyors' safety is improved since the UAV survey does not require the operator to walk on the charcoal heaps holding the GNSS receiver to record the ground points, thus preventing accidents from falling or sliding (Akgul et al. 2018). The increase in survey frequency by UAVs would allow even daily surveys if weather situation and UAV equipment or computational equipment allows. A high survey frequency could overcome the potential limitations of smoke and airborne particles mentioned above, whilst monitoring rates of productivity throughout the year.

\section{Conclusion}

Management improvement in the Brazilian charcoal industry can benefit from more frequent updating of the yard charcoal inventory. As most forestry companies already use UAVs for monitoring planting, harvest planning and stand yield and growth monitoring, the charcoal heaps monitoring could be also hosted by the company and has high potential to be automatized (or at least semiautomatized). The study proposed an innovative methodology for monitoring 
charcoal yards applying digital photogrammetry algorithms from UAV low altitude and near-field imagery. The results indicated that the charcoal heaps volume estimation using UAV derived orthomosaics can replace the conventional method of GNSS RTK surveys with considerable gains in frequency and safety. In case of high accuracy parameterization, besides gains in frequency and safety, you also have gains in geometric precision and accuracy.

\section{References}

Ab Rahman AA, Abdul Maulud KN, Mohd FA, Jaafar O, Tahar KN. 2017. Volumetric Calculation Using Low Cost Unmanned Aerial Vehicle (UAV) Approach. In: IOP Conference Series: Materials Science and Engineering CCLXX.

AGISOFT. 2020. Agisoft Metashape User Manual Professional Edition Version 1.6.

Akgul M, Yurtseven H, Gulci S, Akay AE. 2018. Evaluation of UAV- and GNSSBased DEMs for Earthwork Volume. Arabian Journal for Science and Engineering 43: 1893-1909.

Anifantis AS, Camposeo S, Vivaldi GA, Santoro F, Pascuzzi S. 2019. Comparison of UAV Photogrammetry and 3D Modeling Techniques with Other Currently Used Methods for Estimation of the Tree Row Volume of a Super-High-Density Olive Orchard. Agriculture 9: 233.

Busnello FJ, Tecchio D, Isoton F. 2016. Acurácia entre levantamento topográfico com GNSS pós processamento e RTK para atender ao georreferenciamento de imóveis rurais. Tecnológica 4: 16-25.

Dainelli R, Toscano P, Di Gennaro SF, Matese A. 2021. Recent advances in Unmanned Aerial Vehicles forest remote sensing - A systematic review. Part II: Research applications. Forests 12: 397. 
Feng W, Zhao Y, Zhou L, Huang D, Hassan A. 2020. Fast Cycle Slip Determination for High-Rate Multi-GNSS RTK Using Modified GeometryFree Phase Combination. GPS Solutions 24.

Figueiredo EO, D'Oliveira MVN, Locks CJ, Papa DA. 2016. Estimativa do volume de madeira em pátios de estocagem de toras por meio de câmeras RGB instaladas em aeronaves remotamente pilotadas (ARP). Rio Branco: Embrapa.

Giannetti F, Chirici G, Gobakken T, Næsset E, Travaglini D, Puliti S. 2018. A New Approach with DTM-Independent Metrics for Forest Growing Stock Prediction Using UAV Photogrammetric Data. Remote Sensing of Environment 213: 195-205.

Graybill FA. 1976. Theory and Application of the Linear Model. CA: Duxbury Press.

Gülci S, Akay AE, Gülci N, Tas I. 2021. An assessment of conventional and drone-based measurements for tree attributes in timber volume estimation: A case study on stone pine plantation. Ecological Informatics 63: 101303.

Iglhaut J, Cabo C, Puliti S, Piermattei L, O'Connor J, Rosette J. 2019. Structure from Motion Photogrammetry in Forestry: A Review. Current Forestry Reports 5: 155-68.

Iqbal IA, Osborn J, Stone C, Lucieer A, Dell M, McCoull C. 2018. Evaluating the robustness of point clouds from small format aerial photography over a pinus radiata plantation. Australian Forestry 81: 162-76.

Jayathunga S, Owari T, Tsuyuki S. 2018. Evaluating the performance of photogrammetric products using fixed-wing uav imagery over a mixed conifer-broadleaf forest: Comparison with airborne laser scanning. Remote Sensing 10: 187.

Krause S, Sanders TGM, Mund JP, Greve K. 2019. UAV-Based

Photogrammetric Tree Height Measurement for Intensive Forest Monitoring. Remote Sensing 11: 758. 
Krebs P, Pezzatti GB, Stocker M, Bürgi M, Conedera M. 2017. The Selection of Suitable Sites for Traditional Charcoal Production: Ideas and Practice in Southern Switzerland. Journal of Historical Geography 57: 1-16.

Marushko Y. 2019. Computer Vision: stereo vision and volume measurement. Medium. https://medium.com/@softarex/computer-vision-stereo-vision-andvolume-measurement-910c381f0f75

Mokroš M, Tabačák M, Lieskovský M, Fabrika M. 2016. Unmanned Aerial Vehicle Use for Wood Chips Pile Volume Estimation. In International Archives of the Photogrammetry, Remote Sensing and Spatial Information Sciences - XXIII ISPRS Congress XLI-B1: 953-56.

Mund LP, Katz N, Krause S, Cremer T. 2017 Hackschnitzelhaufenvermessung mittels Drohnentechnik. AFZ-DerWald 26: 36-39.

Okode, MO, Olorunnisola AO, Aremu AK, Onchieku JM. 2020 . Socio-Economic and Environmental Impacts of Charcoal Production in South Gem SubCounty, Siaya County, Kenya. International Journal of Agriculture and Environmental Research 6.

Oliveira AC, Carneiro ACO, Barcellos DC, Rodriguez AV, Amaral BMN, Pereira BLC. 2015. Resfriamento Artificial Em Fornos Retangulares Para a Produção de Carvão Vegetal. Revista Árvore 39: 769-78.

Oliveira WF, Vieira AW, Santos SR. 2020. Quality of forest plantations using aerial images and computer vision techniques. Revista Ciência Agronômica 51: 1-10.

Ota T, Ogawa M, Mizoue N, Fukumoto K, Yoshida S. 2017. Forest Structure Estimation from a UAV-Based Photogrammetric Point Cloud in Managed Temperate Coniferous Forests. Forests 8: 343.

Parra H, Gomes JS, Shebl H. 2017. Integrated Workflow For Building 3d Digital Outcrop Models Using Unmanned Aerial Vehicles-Drones: Field Case Thamama Group, Wadih Rahbah, UAE. In Abu Dhabi International Petroleum Exhibition \& Conference. 
Puliti S, Solberg S, Granhus A. 2019. Use of UAV Photogrammetric Data for Estimation of Biophysical Properties in Forest Stands under Regeneration. Remote Sensing 11.

Raeva PL, Filipova SL, Filipov DG. 2016. Volume Computation of a Stockpile A Study Case Comparing GPS and Uav Measurements in an Open Pit Quarry. In: International Archives of the Photogrammetry, Remote Sensing and Spatial Information Sciences XXIII ISPRS Congress XLI-B1: 999-1004.

Santos IS, Martins MA, Pereira EG, Carneiro ACO. 2020. Physical and thermal properties of eucalyptus wood charcoal. Cerne 26: 109-117.

Seboka Y. 2009. Charcoal Production: Opportunities and Barriers for Improving Efficiency and Sustainability. In: Bio-Carbon Opportunities in Eastern and Southern Africa: Harnessing Carbon Finance to Promote Sustainable Forestry, Agro-Forestry and Bio-Energy: 102-26.

Acknowledgements: We thank the Votorantim Metais for allow the field work in the production site. EBG thanks CNPq for support his research (Grant number 301661/2019-7). We thank the support from FAPEMIG, CNPq, CAPES and UFVJM.

Author Contributions: LMEC, AM, EBG, GJMU, DS and JGS conceptualized and designed the research project. EBG, AM and DS carried out all field work and survey experiments. LMEC, GJMU and EBG did the statistical analysis. All the authors contributed to the writing the manuscript. EBG, JR and JPM contributed in the revision of the draft manuscript and helped rewriting the final version.

Funding: Funding was provided by the Coordenação de Aperfeiçoamento de Pessoal de Nível Superior Brasil (CAPES; Finance Code 001); Conselho Nacional de Desenvolvimento Científico e Tecnológico (Process 301661/2019-7); Universidade Federal dos Vales do Jequitinhonha e Mucuri (UFVJM);

Conflicts of Interest: The authors declare no conflict of interest. The supporting funders had no role in the design of the study; in the collection and interpretation of 
the field data; in the writing of the manuscript, or in the decision to publish the results of our investigation. 